\title{
Influence of previous aspirin treatment and smoking on the electrocardiographic manifestations of injury in acute myocardial infarction
}

\author{
S Kennon, K Barakat, A Suliman, P K MacCallum, K Ranjadayalan, P Wilkinson, \\ A D Timmis
}

\begin{abstract}
Objective-To examine demographic and clinical characteristics of patients with acute myocardial infarction in order to identify factors affecting the electrocardiographic evolution of injury. Methods-Prospective cohort study of 1399 consecutive patients with a first myocardial infarction. Baseline clinical data associated with ST elevation and Q wave development were identified and 12 month survival was estimated.

Results-Smoking had complex effects on the evolution of injury, increasing the odds of ST elevation (odds ratio (OR) 1.61; 95\% confidence interval (CI) 1.08 to 2.36), but reducing the odds of Q wave development (OR $0.69,95 \%$ CI 0.49 to 0.96 ). The effects of previous aspirin treatment were more consistent with reductions in the odds of ST elevation (OR 0.57, 95\% CI 0.35 to 0.94 ) and $\mathrm{Q}$ wave development (OR $0.53,95 \%$ CI 0.34 to 0.84 ). ST elevation and Q wave development were both associated with an adverse prognosis, with estimated 12 month survival rates of $80.6 \%$ (95\% CI $78.2 \%$ to $83.1 \%$ ) and $80.0 \%$ (95\% CI $77.5 \%$ to $82.5 \%$ ), respectively, compared with $86.5 \%$ (95\% CI $81.2 \%$ to $91.9 \%$ ) and $89.9 \%$ (95\% CI $86.2 \%$ to $93.7 \%$ ) for patients without these ECG changes.

Conclusions-The thrombogenicity of the blood may be a major determinant of infarct severity. Smoking increases thrombogenicity and the likelihood of ST elevation, but because coronary occlusion is relatively more thrombotic in smokers, responses to both endogenous and exogenous thrombolysis are better, reducing the risk of $\mathrm{Q}$ wave development. Previous aspirin treatment reduces thrombogenicity, protecting against ST elevation and Q wave development.
\end{abstract}

(Heart 2000;84:41-45)

Keywords: myocardial infarction; smoking; aspirin

Department of Cardiology, Royal Hospitals Trust, London E1, UK K Barakat

A D Timmis

Department of Haematology, Royal Hospitals Trust

P K MacCallum

Department of Cardiology, Newham Healthcare Trust, London E13, UK

S Kennon

A Suliman

K Ranjadayalan

Department of Environmental Epidemiology, London School of Hygiene and Tropical Medicine, Keppel Street, London WC1, UK

P Wilkinson

Correspondence to: Dr Simon Kennon, Heart and Chest Clinic, Southen Hospital, Westcliffe-on-Sea, Essex SSO ORY, UK email: srok@dircon.co.uk

Accepted 23 March 2000
The ECG remains the most useful tool for diagnosing myocardial infarction and provides a simple means of monitoring the evolution of injury. Regional ST elevation occurs within seconds of coronary occlusion and has a high level of diagnostic specificity, though with only moderate sensitivity. ${ }^{12}$ As ST change resolves, pathological Q waves usually develop and are believed to reflect full thickness ventricular injury, although the relation is imprecise. ${ }^{3-5}$ Early recanalisation of the infarct related artery accelerates the resolution of ST change and may protect against $Q$ wave development if injury is restricted to the subendocardium. ${ }^{6-8}$

It has been reported that previous aspirin treatment can modify the presentation of acute myocardial infarction by protecting against $\mathrm{Q}$ wave development. ${ }^{9}$ It was proposed that inhibition of platelet aggregation shifted the balance between prothrombotic and antithrombotic activity at the coronary plaque, favouring early recanalisation and reducing eventual injury. ${ }^{9}$ Thus the haemostatic environment at the time of plaque rupture could have an important effect on the evolution of myocardial infarction and its clinical consequences. ${ }^{9}{ }^{10}$ This effect may be more pronounced than that achieved by the later administration of thrombolytic and aspirin treatment in the emergency room, which, despite improving the long term prognosis, rarely prevents the development of $\mathrm{Q}$ waves. ${ }^{11}$

In the present study, we analysed the demographic and clinical characteristics of a consecutive series of patients with acute myocardial infarction to identify factors affecting the evolution of injury, as reflected by ST elevation and Q wave development on the ECG. We paid particular attention to analysing the effects of previous aspirin treatment and smoking, which have opposing effects on the thrombogenicity of the blood.

\section{Methods}

PATIENT POPULATION

In all, 1829 patients were admitted to the coronary care unit of Newham General Hospital with acute myocardial infarction over a 10 year period starting in January 1988. Because the major endpoints of the study were ST elevation and new $\mathrm{Q}$ wave development, we excluded from the analysis 407 patients with a history of previous myocardial infarction and an additional 23 patients who presented with or developed left bundle branch block. This left a study group of 1399 patients with their first myocardial infarction; 1239 of these presented with or developed ST segment elevation, and in this group 979 developed new Q waves. Myocardial 
Table 1 Baseline characteristics of 1395 patients presenting with acute myocardial infarction stratified by $S T$ elevation

\begin{tabular}{|c|c|c|c|}
\hline & $\begin{array}{l}\text { ST elevation } \\
(n=1239)\end{array}$ & $\begin{array}{l}\text { No ST elevation } \\
(n=156)\end{array}$ & $p$ Value \\
\hline Age (years) & $62.0(54$ to 70$)$ & 64.5 (56.5 to 72.5$)$ & 0.10 \\
\hline Male sex & $897(72.4)$ & $111(71.1)$ & NS \\
\hline \multicolumn{4}{|l|}{ Racial group } \\
\hline African & $40(3.2)$ & $5(3.2)$ & \\
\hline Asian & $318(25.7)$ & $39(25.0)$ & \\
\hline White & $881(71.1)$ & $112(71.8)$ & NS \\
\hline Smoking & $654(54.1)$ & $62(40.8)$ & 0.002 \\
\hline Hypertension & $385(31.5)$ & $45(29.2)$ & NS \\
\hline Diabetes & $248(20.1)$ & $27(17.4)$ & NS \\
\hline \multicolumn{4}{|l|}{ Previous treatment with } \\
\hline Aspirin & $121(10.4)$ & $27(17.8)$ & 0.007 \\
\hline b Blocker & $117(10.1)$ & $18(11.8)$ & NS \\
\hline \multicolumn{4}{|l|}{ Emergency treatment with } \\
\hline Aspirin & $1106(90.4)$ & $147(94.8)$ & 0.07 \\
\hline Thrombolysis & $984(79.7)$ & $52(33.3)$ & $<0.001$ \\
\hline Pain duration $<120 \mathrm{~min}$ & $602(51.7)$ & $43(29.9)$ & $<0.001$ \\
\hline \multicolumn{4}{|c|}{ Admission biochemistry $(\mathrm{mmol} / \mathrm{l})$} \\
\hline Glucose & 8.9 (6.0 to 11.8$)$ & $7.8(6.1$ to 9.5$)$ & 0.01 \\
\hline Potassium & $4.0(3.7$ to 4.3$)$ & $4.2(4.0$ to 4.4$)$ & $<0.001$ \\
\hline \multicolumn{4}{|l|}{ Mortality } \\
\hline 30 Days & $163(13.2)$ & $13(8.3)$ & 0.09 \\
\hline 6 Months & $194(15.7)$ & $16(10.3)$ & 0.08 \\
\hline
\end{tabular}

ST data unavailable in four patients. Data are numbers (percentages), except for age, glucose, and potassium, which are median values (interquartile range).

infarction was diagnosed if any two of the following criteria were fulfilled:

- cardiac chest pain lasting at least 30 minutes;

- ST elevation of $\geqslant 0.1 \mathrm{mV}$ in at least one standard lead or $\geqslant 0.2 \mathrm{mV}$ in two or more contiguous chest leads;

- creatine kinase $\geqslant 400 \mathrm{IU} / 1$ (upper limit of reference range $200 \mathrm{IU} / 1)$.

Thrombolysis was recommended for any patient with regional ST elevation who presented within 12 hours of the onset of continuous chest pain.

\section{DATA COLLECTION}

Baseline clinical characteristics, including demographic, clinical, and biochemical data, were collected prospectively by one of three study investigators and entered into a purpose built electronic database. The hospital diagnosis of a qualifying event (ST elevation or new Q wave development) was determined by one of

Table 2 Baseline characteristics of 1239 patients presenting with acute myocardial infarction and $S T$ elevation, stratified for $Q$ wave development

\begin{tabular}{|c|c|c|c|}
\hline & $\begin{array}{l}Q \text { wave infarction } \\
(n=979)\end{array}$ & $\begin{array}{l}\text { Non- } Q \text { wave infarction } \\
(n=248)\end{array}$ & $p$ Value \\
\hline Age (years) & $62.0(53$ to 71$)$ & $61.0(52.5$ to 69.5$)$ & NS \\
\hline Male sex & $708(72.3)$ & $182(73.4)$ & NS \\
\hline \multicolumn{4}{|l|}{ Racial group } \\
\hline African & $28(2.9)$ & $12(4.8)$ & \\
\hline Asian & $258(26.4)$ & $59(23.8)$ & \\
\hline White & $693(70.8)$ & $177(71.4)$ & NS \\
\hline Smoking & $502(52.6)$ & $148(60.2)$ & 0.03 \\
\hline Hypertension & $303(31.3)$ & $79(32.0)$ & NS \\
\hline Diabetes & $190(19.5)$ & $56(22.6)$ & NS \\
\hline \multicolumn{4}{|l|}{ Previous treatment with: } \\
\hline Aspirin & $84(9.1)$ & $36(15.5)$ & 0.005 \\
\hline$\beta$ Blocker & $90(9.8)$ & $27(11.7)$ & NS \\
\hline \multicolumn{4}{|l|}{ Emergency treatment with: } \\
\hline Aspirin & 865 (89.6) & $230(93.5)$ & 0.07 \\
\hline Thrombolysis & $771(79.1)$ & $204(82.3)$ & NS \\
\hline Pain duration < $120 \mathrm{~min}$ & $473(51.7)$ & $125(52.1)$ & NS \\
\hline \multicolumn{4}{|c|}{ Admission biochemistry $(\mathrm{mmol} / \mathrm{l})$} \\
\hline Glucose & $9.0(5.9$ to 12.1$)$ & $8.5(5.8$ to 11.2$)$ & NS \\
\hline Potassium & $4.0(3.7$ to 4.3$)$ & $4.0(3.7$ to 4.3$)$ & NS \\
\hline \multicolumn{4}{|l|}{ Mortality } \\
\hline 30 Days & $149(15.2)$ & $11(4.4)$ & $<0.001$ \\
\hline 6 Months & $176(18.0)$ & $14(5.6)$ & $<0.001$ \\
\hline
\end{tabular}

$\mathrm{Q}$ wave data unavailable in 12 patients. Data are numbers (percentages), except for age, glucose, and potassium, which are median values (interquartile range).
Table 3 Multivariate predictors of presenting with or developing ST elevation, based on 1205 complete datasets

\begin{tabular}{llll}
\hline & $\begin{array}{c}\text { Odds } \\
\text { ratio }\end{array}$ & 95\% CI & p Value \\
\hline Age & 1.00 & 0.98 to 1.02 & 0.95 \\
Male sex & 1.01 & 0.66 to 1.54 & 0.98 \\
Smoking & 1.60 & 1.08 to 2.36 & 0.02 \\
$\begin{array}{l}\text { Hypertension } \\
\text { Diabetes }\end{array}$ & 1.15 & 0.77 to 1.73 & 0.49 \\
$\begin{array}{l}\text { Previous treatment with } \\
\quad \text { aspirin }\end{array}$ & 1.23 & 0.77 to 1.98 & 0.39 \\
$\begin{array}{l}\text { Emergency treatment } \\
\quad \text { with aspirin }\end{array}$ & 0.57 & 0.35 to 0.94 & 0.03 \\
$\begin{array}{l}\text { Pain duration < } 120 \text { min } \\
\quad\end{array}$ & 0.63 & 0.28 to 1.40 & 0.26 \\
\hline
\end{tabular}

Odds ratios represent odds of ST elevation.

two attending cardiologists (KR and $\mathrm{ADT}$ ). The duration of pain before presentation at hospital was recorded, as was emergency treatment with aspirin and thrombolytic agents. Diabetes was recorded in patients on insulin, oral hypoglycaemic drugs, or dietary restrictions. Hypertension was recorded in patients taking antihypertensive drugs. Current smokers were classified as smokers, while exsmokers and non-smokers were grouped as non-smokers. Blood samples were taken in the emergency department for measurement of glucose and potassium concentrations.

FOLLOW UP

The purpose of the follow up was to define all cause mortality and recurrent ischaemic events (readmission with unstable angina or acute myocardial infarction) from the admission date until censoring in July 1998. The patients were flagged by the Office of National Statistics to obtain follow up mortality data. In patients known to be alive at the censoring date and in whom information about non-fatal ischaemic events was not already available from outpatient follow up or readmission to the coronary care unit, postal questionnaires were used to obtain this information, backed up by telephone inquiry for non-responders. In this way, follow up data beyond discharge were obtained in $98 \%$ of the study group.

STATISTICAL ANALYSIS

Survival was calculated by the Kaplan-Meier method, and survival probabilities were expressed as percentages with $95 \%$ confidence intervals (CI). Comparison of discrete variables was by $\chi^{2}$ analysis and continuous variables by the Mann-Whitney U test. In order to evaluate their independent influence,

Table 4 Multivariate predictors of $Q$ wave development in patients with ST elevation based on 1060 complete datasets

\begin{tabular}{llll}
\hline & $\begin{array}{c}\text { Odds } \\
\text { ratio }\end{array}$ & 95\% CI & p Value \\
\hline Age & 1.00 & 0.99 to 1.02 & 0.89 \\
Male sex & 0.95 & 0.67 to 1.35 & 0.49 \\
$\quad$ Smoking & 0.69 & 0.49 to 0.96 & 0.03 \\
$\begin{array}{l}\text { Hypertension } \\
\text { Diabetes }\end{array}$ & 0.89 & 0.64 to 1.24 & 0.49 \\
$\begin{array}{l}\text { Previous treatment with } \\
\quad \text { aspirin }\end{array}$ & 0.67 & 0.46 to 0.97 & 0.03 \\
$\begin{array}{l}\text { Emergency treatment with } \\
\quad \text { aspirin }\end{array}$ & 0.53 & 0.34 to 0.84 & 0.007 \\
$\quad \begin{array}{llll}\text { Thrombolytic treatment } \\
\text { Pain duration < } 120 \text { min }\end{array}$ & 0.72 & 0.39 to 1.32 & 0.28 \\
& 1.00 & 0.67 to 1.50 & 1.00 \\
& & 0.74 to 1.35 & 0.99
\end{tabular}

Odds ratios represent odds of $\mathrm{Q}$ wave infarction. 
Table 5 Influence of smoking, previous aspirin treatment, both, and neither on ST elevation $(n=1287)$ and $Q$ wave development $(n=1130)$ in acute myocardial infarction

\begin{tabular}{lllllc}
\hline & Smoking & Previous aspirin & Both & Neither & p Value \\
\hline ST elevation & $565(91.1)$ & $68(77.3)$ & $51(89.5)$ & $454(87.0)$ & 0.001 \\
Q wave development & $442(78.8)$ & $49(73.1)$ & $33(64.7)$ & $375(83.1)$ & 0.006 \\
\hline
\end{tabular}

Data, number (percentages), are for patients in whom datasets for each of the four variables were complete.

variables showing significant differences or pronounced trends in univariate analysis or believed to be of clinical or biological relevance were entered into a logistic regression analysis. Improvements in model fit were based on comparison of likelihood ratios. Odds ratios (OR) are quoted together with 95\% CI.

\section{Results}

BASELINE CHARACTERISTICS: ST ELEVATION These data are given in table 1 . Comparison of baseline characteristics in patients with and without ST elevation showed no significant differences with regard to age, sex distribution, or race. At the time of admission, significantly more patients with ST elevation were current smokers but fewer were taking aspirin. Patients with ST elevation presented earlier after the onset of chest pain than those without, and tended to have higher glucose but lower potassium concentrations in their admission blood samples. Significantly more patients with ST elevation received thrombolytic treatment in accordance with treatment guidelines.

BASELINE CHARACTERISTICS: Q WAVES

Comparison of baseline characteristics in patients with ST elevation who did and did not develop pathological $Q$ waves showed no significant differences as regards age, sex distribution, and racial group (table 2). Signifi-
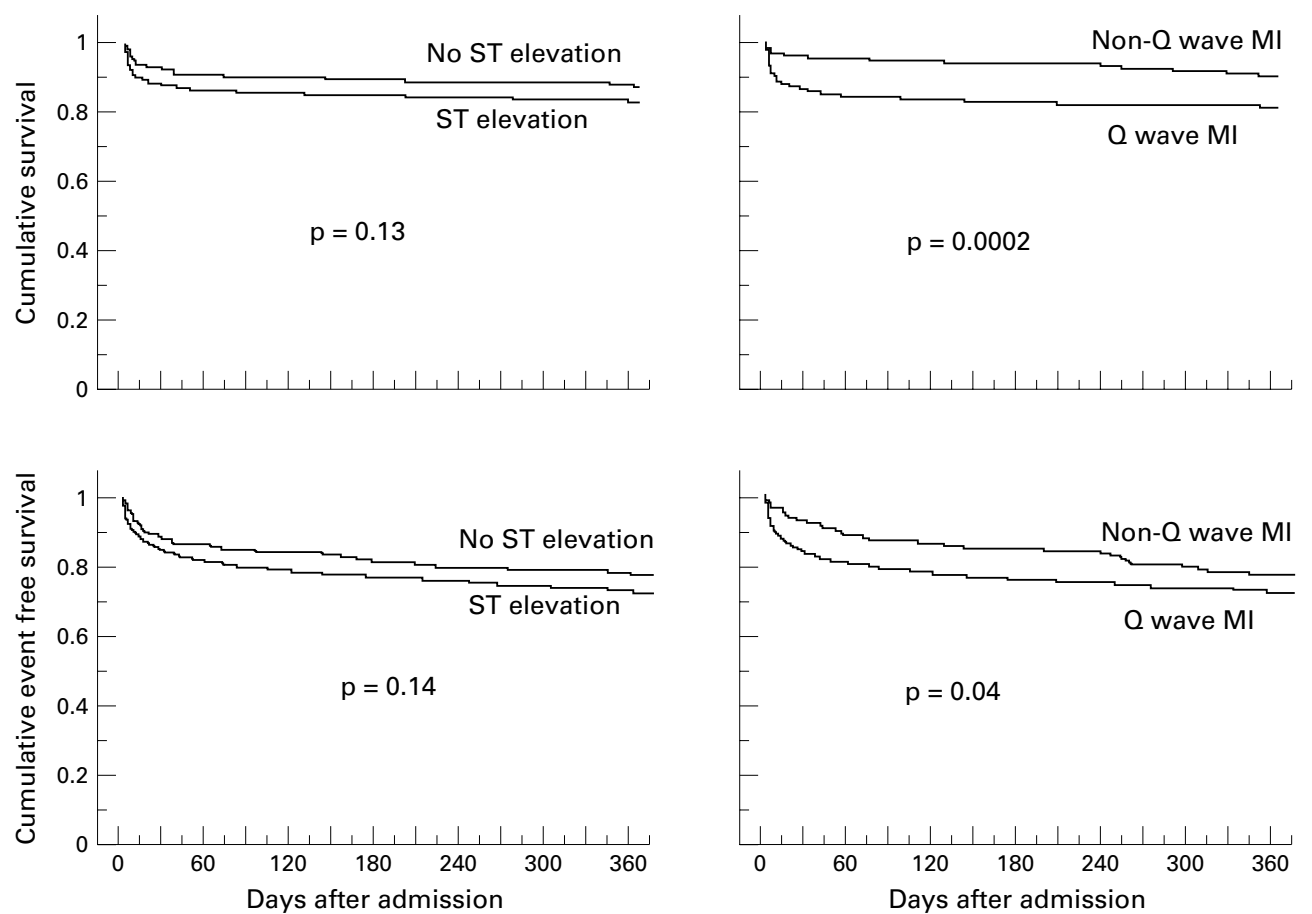

Figure 1 Kaplan-Meier survival curves illustrating effects of ST elevation and $Q$ wave development on 12 month survival (upper panels) and 12 month survival without myocardial infarction or admission with unstable angina (lower panels).

cantly fewer patients who developed $\mathrm{Q}$ waves were current smokers and fewer were taking aspirin at the time of admission. Proportions who received emergency treatment with aspirin and thrombolysis were similar in both groups. Comparison of smokers who did $(n=516)$ and did not $(n=134)$ receive thrombolytic treatment showed similar rates of $\mathrm{Q}$ wave development $(76.9 \%$ v $78.4 \%)$.

PREDICTORS OF ST ELEVATION AND Q WAVE DEVELOPMENT

These data are given in tables 3 and 4 . Smoking increased the odds of ST elevation by $60 \%$ but reduced the odds of $\mathrm{Q}$ wave development by $31 \%$. Being on aspirin at the time of admission reduced the odds of ST elevation and Q wave development by $43 \%$ and $47 \%$, respectively. Diabetes also reduced the odds of $\mathrm{Q}$ wave development. Admission within two hours of the onset of chest pain more than doubled the odds of ST elevation but did not influence $\mathrm{Q}$ wave development.

RELATIONS BETWEEN PREVIOUS ASPIRIN TREATMENT, SMOKING, ST ELEVATION, AND Q WAVE DEVELOPMENT

ST elevation occurred most commonly in smokers and least commonly in patients on previous aspirin treatment (table 5). Q wave development occurred most commonly in patients who neither smoked nor took aspirin, and least commonly in those who both smoked and took aspirin. For other groups, rates of ST elevation and $\mathrm{Q}$ wave development were intermediate.

SURVIVAL ANALYSIS

ST elevation and Q wave development were both associated with an increase in all cause 
mortality as well as recurrent ischaemic events in the form of non-fatal myocardial infarction and readmission with unstable angina (fig 1). The estimated 12 month survival rates were $80.6 \%$ (95\% CI $78.2 \%$ to $83.1 \%$ ) for patients presenting with ST elevation and $80.0 \%(95 \%$ CI $77.5 \%$ to $82.5 \%$ ) for patients who developed Q waves, compared with $86.5 \%$ (95\% CI $81.2 \%$ to $91.9 \%)$ and $89.9 \%$ (95\% CI $86.2 \%$ to $93.7 \%$ ), respectively, for patients without these ECG changes. Similarly, estimated 12 month event free survival rates were $71.0 \%$ (95\% CI $67.4 \%$ to $74.6 \%)$ and $69.6 \%$ (95\% CI $66.7 \%$ to $72.5 \%$ ) compared with $76.0 \%$ (95\% CI $69.3 \%$ to $82.8 \%)$ and $74.7 \%$ (95\% CI $69.1 \%$ to $80.3 \%$ ).

\section{Discussion}

This prospective cohort study of patients with acute myocardial infarction has shown important independent effects of smoking and previous aspirin treatment on ST segment change and $\mathrm{Q}$ wave development that have not been reported previously. The effects of smoking were complex, associations with ST elevation being consistent with its prothrombotic activity but apparently inconsistent with the nondevelopment of $\mathrm{Q}$ waves. The effects of previous aspirin treatment were generally favourable and likely to reflect its antiplatelet activity.

\section{ST ELEVATION}

ST elevation in people with chest pain is a reliable marker of coronary occlusion and usually predicts $\mathrm{Q}$ wave development. ${ }^{12}$ In this study, previous aspirin treatment reduced the incidence of ST elevation, whereas smoking was predictive of ST elevation. This presumably reflects first, the antiplatelet effects of aspirin, which shift the endogenous balance of thrombotic and thrombolytic activity in favour of early coronary patency, and second, the prothrombotic effects of smoking, ${ }^{13-15}$ which exaggerate the thrombotic response to plaque rupture and increase the risk of total rather than partial coronary occlusion. This is consistent with earlier studies of acute coronary syndromes in which smokers were more likely to present with myocardial infarction than unstable angina, while previous aspirin treatment favoured presentation with unstable angina. ${ }^{9-11}$

\section{Q WAVE DEVELOPMENT}

The reduced incidence of $Q$ wave development in patients on previous aspirin treatment is consistent with the antiplatelet effect of aspirin. In contrast, the association between smoking and non-Q wave infarction appears paradoxical. However, it is well established that high grade reflow following thrombolysis is more common in smokers than in non-smokers; this is thought to reflect a thrombotic rather than an atherosclerotic coronary occlusion, which is more susceptible to thrombolysis. ${ }^{16-19}$ It is plausible, therefore, that the prothrombotic effects of smoking account not only for its association with ST elevation but also for its association with non-Q wave infarction, by providing a substrate for successful thrombolysis. It may also explain why smokers with acute myocardial infarction often have a relatively good short term prognosis, as absence of $\mathrm{Q}$ waves usually denotes more limited myocardial injury. ${ }^{16-21}$ Thrombolytic treatment clearly has beneficial effects on prognosis, but a lower mortality in smokers was documented in studies in the prethrombolytic $\mathrm{era}^{21}$ and, in common with other investigators, ${ }^{11}$ we found that neither thrombolytic treatment nor aspirin given after hospital arrival influenced $Q$ wave development, even though the median arrival time for this inner city population was only just over two hours after the onset of chest pain. However, if smokers are also more susceptible than non-smokers to endogenous lytic mechanisms shortly after the plaque event, recanalisation would occur sufficiently early to protect against $\mathrm{Q}$ wave development. Thus previous studies have shown that in acute myocardial infarction coronary patency at the time of presentation commonly predicts non- $Q$ wave infarction, ${ }^{8}$ even in patients with ST elevation on the presenting ECG. ${ }^{6} 7$ This emphasises how the haemostatic environment at the time of plaque rupture, which is modified both by previous aspirin treatment and smoking, can have more profound effects on its clinical consequences than antithrombotic treatment given after hospital arrival.

PAIN DURATION AND ADMISSION BIOCHEMISTRY The duration of symptoms was a major predictor of ST change. Thus ST elevation was more common in patients presenting within two hours after the onset of chest pain than in those presenting later. This is consistent with the work of DeWood and colleagues, who showed that as time elapses after the onset of myocardial infarction the incidence of complete coronary occlusion declines, presumably reflecting endogenous thrombolytic activity. ${ }^{12}$ Increased pain severity may also have contributed to the earlier presentation of patients with ST elevation and this would predict a heightened sympathoadrenal response, which no doubt explains the tendency for blood glucose to be higher and potassium lower in patients with ST elevation. ${ }^{22}$ Not surprisingly, however, admission biochemistry was unrelated to the later development of $\mathrm{Q}$ waves, although patients who were diabetic were more likely to have non-Q-wave infarction. This has been reported previously ${ }^{24}$ and may reflect the diffuse and chronic nature of diabetic coronary disease which encourages collateralisation of the myocardium and protects against ischaemic injury in the event of thrombotic coronary occlusion. $^{25}$

\section{PROGNOSIS}

The effects of smoking and previous aspirin treatment on the evolution of ECG changes in acute myocardial infarction are likely to have important clinical consequences, particularly regarding longer term prognosis. We and others $^{26} 27$ have previously reported that patients with ST elevation have a worse prognosis than those without, an observation supported 
by the data in the present study. The high proportion of patients presenting with ST elevation in this study may reflect not only the inner city location of our hospital, which ensures that patients with myocardial infarction present early (almost half presented within two hours after the onset of pain), but also the protective effect of myocardial collateralisation. ${ }^{28-30}$ The extent of myocardial collateralisation is dependent upon the severity and duration of ischaemic heart disease, and other studies with a lower proportion of patients presenting with ST elevation ${ }^{31}{ }^{32}$ have not excluded those with previous myocardial infarction. There are conflicting data on the relevance of Q wave development for prognosis. Our data, however, are in agreement with those of Barbagelata and colleagues, who have also reported a lower one year mortality for non-Q wave infarction in a large cohort of patients presenting with their first myocardial infarct. ${ }^{33}$ Of course, any prognostic benefits of smoking that are related to the non-development of $\mathrm{Q}$ waves must be minimal when set against the overall increase in coronary risk. However, the effects of previous aspirin treatment in protecting against ST elevation and $\mathrm{Q}$ wave development in acute myocardial infarction may contribute to its benefit in coronary artery disease.

CONCLUSIONS

The thrombogenicity of the blood at the time of a plaque event may be a major determinant of infarct severity, as reflected by ST segment change and $\mathrm{Q}$ wave development. Our study suggests that smoking, which increases thrombogenicity, has complex effects, increasing the likelihood of ST elevation while at the same time providing a substrate for successful thrombolysis, which reduces the risk of $\mathrm{Q}$ wave development. The net effect on prognosis may be beneficial. On the other hand, previous aspirin treatment may, by reducing thrombogenicity, reduce infarct severity, protecting against ST elevation and Q wave development more effectively than aspirin given after hospital arrival.

1 Rude RE, Poole WK, Muller JE, et al. Electrocardiographic and clinical criteria for recognition of acute myocardial inf-
arction based on analysis of 3,697 patients. Am 7 Cardio arction based on

2 Yusuf S, Pearson M, Sterry H, et al. The entry ECG in the early diagnosis and prognostic stratification of patients with acute myocardial infarction. Eur Heart f 184;5:690-6.

3 Nicholson MR, Roubin GS, Bernstein L, et al. Prognosis after an initial non- $Q$ wave myocardial infarction related to coronary arterial anatomy. Am 7 Cardiol 1983;52:462-5.

4 Schulze RA, Pitt B, Griffith LSC, et al. Coronary angiography and left ventriculography in survivors of transmural and nontransmural myocardial infarction. $A m \mathcal{F}$ Med 1978;64:108-13.

5 Madigan NP, Rutherford BD, Frye RL. The clinical course, early prognosis and coronary anatomy of subendocardial infarction. Am $\mathcal{F}$ Med 1976;60:634-41.

6 Timmis AD, Griffin B, Crick JC, et al. The effects of early coronary patency on the evolution of myocardial infarction: a prospective arteriographic study. Br Heart $\mathcal{f}$ 1987;58: a prospecti $345-51$.

7 Hackworthy RA, Vogel MB, Harris PJ. Relationship between changes in ST segment elevation and patency of the infarct-related coronary artery in acute myocardial infarction. Am Heart f 1986;112:279-84.
8 DeWood MA, Stiffer WF, Simpson CS, et al. Coronary arteriographic findings soon after non- $\mathrm{Q}$ wave myocardial infarction. N Engl f Med 1986;315:417-23.

9 Garcia-Dorado D, Theroux P, Tornos P, et al. Previous aspirin use may attenuate the severity of the manifestation of acute ischemic syndromes. Circulation 1995;92:1743-8.

10 Kennon S, Suliman A, MacCallum PK, et al. Clinical characteristics determining the mode of presentation in patients with acute coronary syndromes. F Am Coll Cardiol 1998;32: 2018-22.

11 Col NF, Yarzbski J, Gore JM, et al. Does aspirin consumption affect the presentation or severity of acute

12 DeWood MA, Spores J, Notske R, et al. Prevalence of total coronary occlusion during the early hours of transmural myocardial infarction. $N$ Engl F Med 1980;303:897-902

13 Blache D. Involvement of hydrogen and lipid peroxides in acute tobacco-induced platelet hyperactivity. Am F Physiol 1995;268:679-85.

14 Lowe GDO, Fowkes FGR, Dawes J, et al. Blood viscosity, fibrinogen and activation of coagulation and leucocytes in peripheral arterial disease and the normal population in the Edinburgh Artery Study. Circulation 1993;87:1915-20.

15 Simpson AJ, Gray RS, Moore NR, et al. The effects of chronic smoking on the fibrinolytic potential of plasma and platelets. Br f Haematol 1997;97:208-13.

16 Ishihara M, Sato H, Tateishi H, et al. Clinical implications of cigarette smoking in acute myocardial infarction: acute angiographic findings and long-term prognosis. Am Heart $\mathcal{F}$ 1997;134:955-60.

17 Barbash GI, Reiner J, White HD, et al. Evaluation of paradoxic beneficial effects of smoking in patients receiving hrombolytic therapy for acute myocardial infarction: mechanism of the "smoker's paradox" from the GUSTO-I trial, with angiographic insights. F Am Coll Cardiol 1995;26: 1222-9.

18 Barbash GI, White HD, Modan M, et al. Significance of smoking in patients receiving thrombolytic therapy for acute myocardial infarction. Experience gleaned from the nternational tissue plasminogen activator/streptokinase mortality trial. Circulation 1993;87:53-8.

19 Grines CL, Topol EJ, O'Neill WW, et al. Effect of cigarette smoking on outcome after thrombolytic therapy for myocardial infarction. Circulation 1995;91:298-303.

20 Stevenson R, Ranjadayalan K, Wilkinson P, et al. Short and long term prognosis of acute myocardial infarction since introduction of thrombolysis. BMF 1993;307:349-53.

21 Molstad P. First myocardial infarction in smokers. Eur Heart f 1991;12:753-9.

22 Nordrehaug JE, Johannessen K-A, Von der Lippe G, et al. Effect of timolol on changes in serum potassium concentration during acute myocardial infarction. Br Heart $\mathcal{f}$ 1985;53:388-93.

23 Oswald GA, Smith CCT, Betteridge DJ, et al. Determinants and importance of stress hyperglycaemia in non-diabetic patients with myocardial infarction. BMF 1986;293:91722 .

24 Karlson BW, Herlitz J, Richter A, et al. Prognosis in acute Karlson BW, Herlitz J, Richter A, et al. Prognosis in acute
myocardial infarction in relation to development of $\mathrm{Q}$ myocardial infarction in relation to

25 Stone PH, Muller JE, Hartwell T, et al. The effect of diabetes mellitus on prognosis and serial left ventricular function after acute myocardial infarction: contribution of both coronary disease and diastolic left ventricular dysfunction to the adverse prognosis. The MILIS Study Group. F Am Coll Cardiol 1989;14:49-57.

26 Laji K, Wilkinson P, Ranjadayalan K, et al. Prognosis in acute myocardial infarction: comparison of patients with diagnostic and nondiagnostic electrocardiograms. $\mathrm{Am}$ Heart f 1995;130:705-10.

27 Yusuf S, Pearson M, Sterry H, et al. The entry ECG in the early diagnosis and prognostic stratification of patients with acute myocardial infarction. Eur Heart 7 1984;5:690-6.

28 Macdonald RG, Hill JA, Feldman RL. ST segment response to acute coronary occlusion: coronary hemodynamic and to acute coronary occlusion: coronary hemodynamic and
angiographic determinants of direction of ST segment angiographic determinants of dire
shift. Circulation 1986;74:973-9.

29 Yamagishi $M$, Kuzuya $\mathrm{T}$, Kodama $\mathrm{K}$, et al. Functional significance of transient collaterals during coronary artery spasm. Am f Cardiol 1985;56:407-12.

30 Christian TF, Gibbons RJ, Clements IP, et al. Estimates of myocardium at risk and collateral flow in acute myocardial infarction using electrocardiographic indexes with comparison to radionuclide and angiographic measures. $\mathcal{f}$ Am Coll Cardiol 1995;26:388-93

31 Herlitz J, Karlson BW, Bang A, et al. Mortality and risk indicators for death during five years after acute myocardial infarction among patients with and without ST elevation infarction among patients with and without ST elevation

32 Dalzell GW, Purvis J, Adgey AA. The initial electrocardiogram in patients seen by a mobile coronary care unit. $Q \mathcal{F}$ gram in patients seen

33 Barbagelata A, Califf RM, Sgarbossa EB, et al. Thrombolyis and $\mathrm{Q}$ wave versus non- $\mathrm{Q}$ wave first acute myocardial infarction: a GUSTO-I substudy. I Am Coll Cardiol 1997;29:770-7. 